
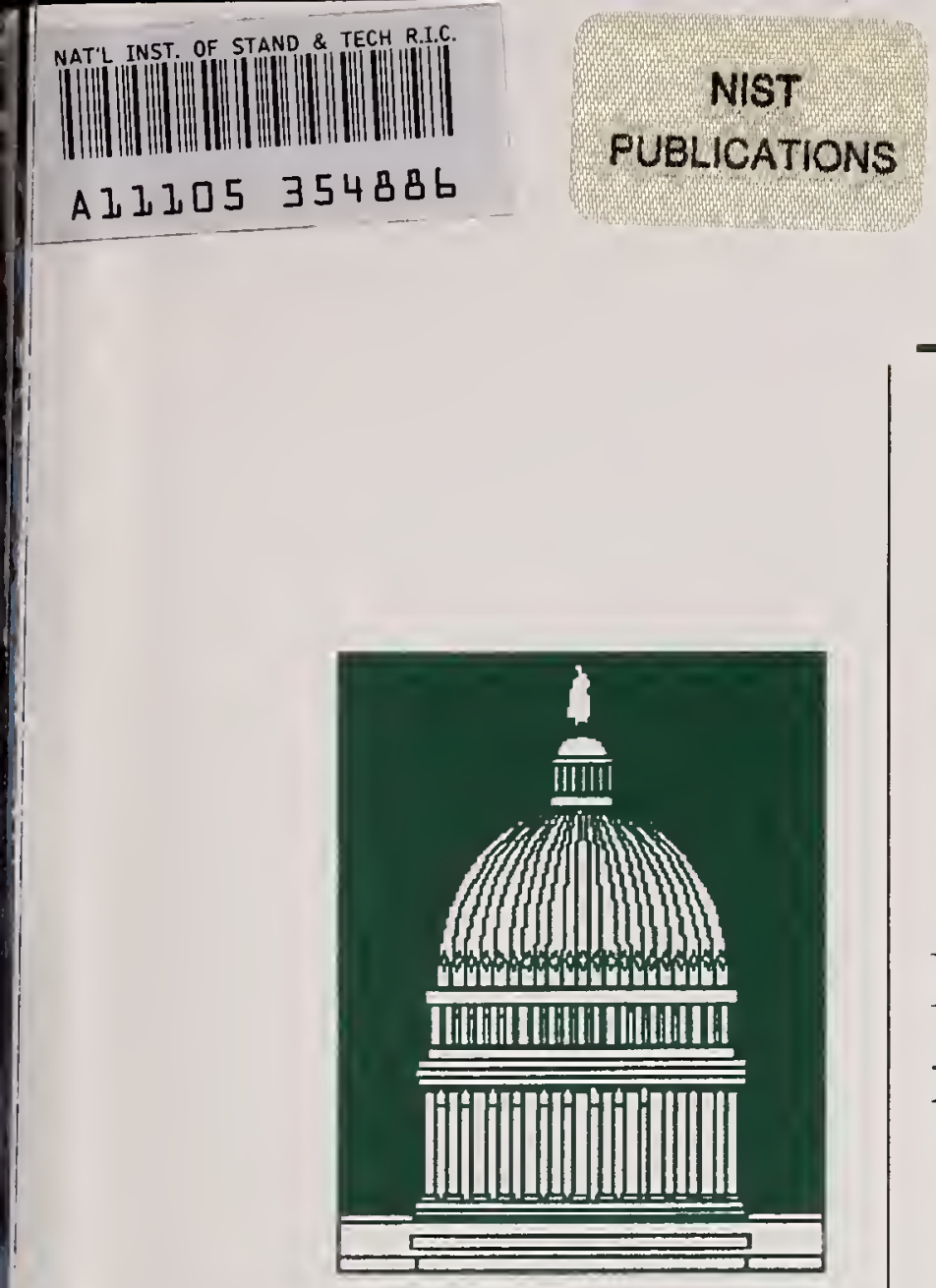

\title{
Federal Implementation Guideline for Electronic Data Interchange
}

\section{ASC X12 003050 Transaction Set 839F Project Cost Reporting}

\section{Implementation Convention}

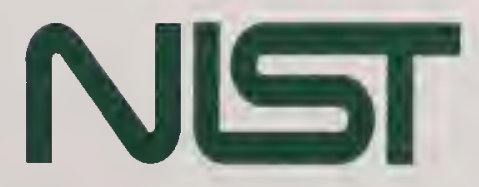

U.S. DEPARTMENT OF COMMERCE

Technology Administration

National Institute of

Standards and Technology

$Q C$

100

.457

N0.881-31

1998 

to ensure product reliability ... and to facilitate rapid commercialization ... of products based on new scientific discoveries."

NIST, originally founded as the National Bureau of Standards in 1901, works to strengthen U.S. industry's competitiveness; advance science and engineering; and improve public health, safety, and the environment. One of the agency's basic functions is to develop, maintain, and retain custody of the national standards of measurement, and provide the means and methods for comparing standards used in science, engineering, manufacturing, commerce, industry, and education with the standards adopted or recognized by the Federal Government.

As an agency of the U.S. Commerce Department's Technology Administration, NIST conducts basic and applied research in the physical sciences and engineering, and develops measurement techniques, test methods, standards, and related services. The Institute does generic and precompetitive work on new and advanced technologies. NIST's research facilities are located at Gaithersburg, MD 20899, and at Boulder, CO 80303. Major technical operating units and their principal activities are listed below. For more information contact the Publications and Program Inquiries Desk, 301-975-3058.

\section{Office of the Director}

- National Quality Program

- International and Academic Affairs

\section{Technology Services}

- Standards Services

- Technology Partnerships

- Measurement Services

- Technology Innovation

- Information Services

\section{Advanced Technology Program}

- Economic Assessment

- Information Technology and Applications

- Chemical and Biomedical Technology

- Materials and Manufacturing Technology

- Electronics and Photonics Technology

\section{Manufacturing Extension Partnership Program}

- Regional Programs

- National Programs

- Program Development

\section{Electronics and Electrical Engineering} Laboratory

- Microelectronics

- Law Enforcement Standards

- Electricity

- Semiconductor Electronics

- Electromagnetic Fields'

- Electromagnetic Technology ${ }^{1}$

- Optoelectronics ${ }^{1}$

\section{Chemical Science and Technology}

\section{Laboratory}

- Biotechnology

- Physical and Chemical Properties ${ }^{2}$

- Analytical Chemistry

- Process Measurements

- Surface and Microanalysis Science
Physics Laboratory

- Electron and Optical Physics

- Atomic Physics

- Optical Technology

- Ionizing Radiation

- Time and Frequency'

- Quantum Physics ${ }^{1}$

\section{Materials Science and Engineering} Laboratory

- Intelligent Processing of Materials

- Ceramics

- Materials Reliability'

- Polymers

- Metallurgy

- NIST Center for Neutron Research

\section{Manufacturing Engineering}

\section{Laboratory}

- Precision Engineering

- Automated Production Technology

- Intelligent Systems

- Fabrication Technology

- Manufacturing Systems Integration

\section{Building and Fire Research} Laboratory

- Structures

- Building Materials

- Building Environment

- Fire Safety Engineering

- Fire Science

\section{Information Technology Laboratory}

- Mathematical and Computational Sciences ${ }^{2}$

- Advanced Network Technologies

- Computer Security

- Information Access and User Interfaces

- High Performance Systems and Services

- Distributed Computing and Information Services

- Software Diagnostics and Conformance Testing 


\section{Federal Implementation Guideline for Electronic Data Interchange}

\section{ASC X12 003050 Transaction Set 839F Project Cost Reporting}

\section{Implementation Convention}

Electronic Commerce Acquisition Program Management Office Standard Management Committee - Secretariat National Institute of Standards and Technology

Gaithersburg, MD 20899-0001

Editor: Dr. Jean-Philippe Favreau

January 1998

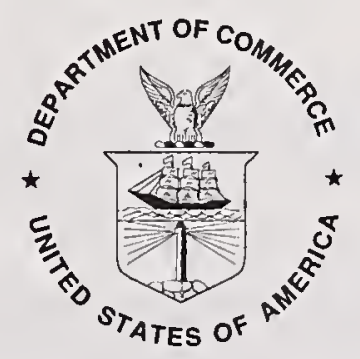

U.S. DEPARTMENT OF COMMERCE

William M. Daley, Secretary

Technology Administration

Gary R. Bachula, Acting Under Secretary for Technology

National Institute of Standards and Technology

Raymond G. Kammer, Director 


\section{Reports on Information Technology}

The National Institute of Standards and Technology (NIST)'s Information Technology Laboratory (ITL) develops standards and guidelines, provides technical assistance, and conducts research for computers and resources. As part of the overall federal effort to establish a single face to industry for conducting electronic commerce, ITL has been designated as the organization responsible for coordinating the development of Federal Implementation Conventions (ICs) for Electronic Data Interchange (EDI). ICs are defined by functional-area experts who create and select options from standard EDI Transaction Sets to yield the implementations to be used for practical EDI. These ICs are made available to federal agencies and industry by electronic means and this Special Publication Series.

\section{National Institute of Standards and Technology Special Publication 881-31 Natl. Inst. Stand. Technol. Spec. Publ. 881-31, 33 pages (Jan. 1998) CODEN: NSPUE2}

\section{U.S. GOVERNMENT PRINTING OFFICE WASHINGTON: 1998}

For sale by the Superintendent of Documents, U.S. Government Printing Office, Washington, DC 20402 


\section{Project Cost Reporting}

\section{Functional Group ID=PK}

\section{Introduction:}

This Draft Standard for Trial Use contains the format and establishes the data contents of the Project Cost Reporting Transaction Set (839) for use within the context of an Electronic Data Interchange (EDI) environment. This transaction set provides the transmission of cost and schedule information to support performance measurement (earned value), program management reporting, and contract funds status reporting. This transaction set will also support the Department of Defense (DoD), Department of Energy (DoE), NASA, and other government agency Cost/Schedule Control Systems Criteria (C/SCSC) and funds status reporting requirements. It is designed to serve the needs of government agencies, prime contractors, and their subcontractors.

\section{Notes:}

\section{This implementation convention addresses how the 839 Project Cost Reporting transaction set can be used to send Contract Funds Status Report (CFSR) data electronically to a government customer.}

2. This implementation convention is designed to be used when a Contract Data Requirements List (CDRL) for a given contract specifies the Contract Funds Status Report (CFSR) Data Item Description (DID) DI-MGMT81468 .

3. There are two appendices for this implementation convention. The example appendix provides additional reference information on how this transaction set is used to exchange funds data electronically. The other appendix is a form cross reference table that outlines how the CFSR DID requirements are mapped to the XI2 standard EDI format.

\begin{tabular}{|c|c|c|c|c|c|c|c|}
\hline Must Use & $\begin{array}{l}\text { Pos. } \\
\text { No. } \\
010\end{array}$ & $\begin{array}{l}\text { Seg. } \\
\underline{\text { ID }} \\
\text { ST }\end{array}$ & $\frac{\text { Name }}{\text { Transaction Set Header }}$ & $\begin{array}{l}\text { Req. } \\
\text { Des. } \\
M\end{array}$ & $\frac{\text { Max.Use }}{1}$ & $\begin{array}{c}\text { Loop } \\
\text { Repeat }\end{array}$ & $\begin{array}{l}\text { Notes and } \\
\text { Comments }\end{array}$ \\
\hline \multirow[t]{2}{*}{ Must Use } & 020 & $\mathrm{BCS}$ & Beginning Segment for Project Cost Reporting & M & 1 & & \\
\hline & 030 & REF & Reference Numbers & $\mathrm{O}$ & 100 & & \\
\hline Not Used & 040 & DLV & Deliverable Information & $\mathrm{O}$ & 10 & & \\
\hline Must Use & 050 & AMT & Monetary Amount & $\mathrm{O}$ & 30 & & \\
\hline Not Used & 060 & PCT & Percent Amounts & $\mathrm{O}$ & 30 & & \\
\hline \multirow[t]{2}{*}{ Must Use } & 070 & DTM & Date/Time Reference & $\mathrm{O}$ & 30 & & \\
\hline & & & LOOP ID - CFT & & & 100 & \\
\hline Must Use & 080 & CFT & Cost Reporting Format Type & M & 1 & & \\
\hline \multirow[t]{2}{*}{ Must Use } & 085 & CAL & Calendar & $\mathrm{O}$ & 50 & & \\
\hline & & & $\overline{L O O P ~ I D ~-~ B S D ~}$ & & & $>1$ & \\
\hline \multirow[t]{3}{*}{ Must Use } & 090 & BSD & Breakdown Structure Description & $\mathrm{O}$ & 1 & & \\
\hline & 100 & REF & Reference Numbers & $\mathrm{O}$ & 100 & & \\
\hline & 105 & DTM & Date/Time Reference & $\mathrm{O}$ & 50 & & \\
\hline Must Use & 110 & AMT & Monetary Amount & $\mathrm{O}$ & 100 & & \\
\hline \multirow[t]{2}{*}{ Not Used } & 115 & QTY & Quantity & $\mathrm{O}$ & 100 & & \\
\hline & 120 & PAM & Period Amount & $\mathrm{O}$ & 100 & & \\
\hline \multirow[t]{3}{*}{ Not Used } & 130 & PCT & Percent Amounts & $\mathrm{O}$ & 100 & & \\
\hline & 140 & MSG & Message Text & $\mathrm{O}$ & 1000 & & \\
\hline & & & LOOP ID - N1 & & & 200 & \\
\hline \multirow[t]{2}{*}{ Must Use } & 150 & $\mathrm{~N} 1$ & Name & M & 1 & & $\mathrm{n} 1$ \\
\hline & 160 & N2 & Additional Name Information & $\mathrm{O}$ & 1 & & \\
\hline
\end{tabular}


839F Project Cost Reporting (Funds Status)

$170 \quad \mathrm{~N} 3 \quad$ Address Information

180 N4 Geographic Location

Must Use $190 \quad$ PER

Administrative Communications Contact

0

Not Used $195 \quad$ REF

Reference Numbers

$\mathrm{O}$

O

Must Use $200 \quad$ DTM

Date/Time Reference

0

Must Use 210

SE

Transaction Set Trailer

M

1

10

10

10

\section{Transaction Set Notes}

1. At least one iteration of the N1 loop is required to identify the contractor. 
839F Project Cost Reporting (Funds Status)

Segment: $\quad$ ST Transaction Set Header

Position: 010

Loop:

Level:

Usage: Mandatory

Max Use: 1

Purpose: To indicate the start of a transaction set and to assign a control number

Syntax Notes:

Semantic Notes: 1 The transaction set identifier (ST01) used by the translation routines of the interchange partners to select the appropriate transaction set definition (e.g., 810 selects the Invoice Transaction Set).

Comments:

Ref. Data

Des. Element Name

Data Element Summary

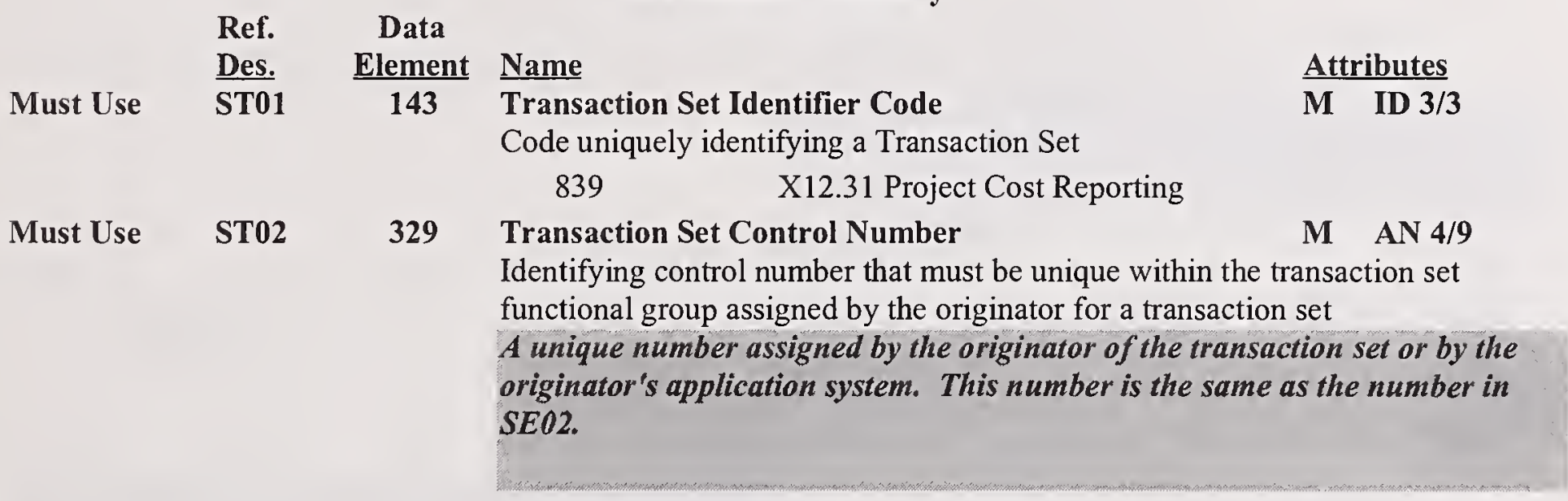


Segment: $\quad$ BCS Beginning Segment for Project Cost Reporting

Position: 020

Loop:

Level:

Usage: Mandatory

Max Use: 1

Purpose: To indicate the beginning of the project cost reporting transaction set, and information to

Syntax Notes:

Semantic Notes:

Comments:

identify a program name, number, contract type, and security classification.

$1 \mathrm{BCS02}$ is the transaction set date.

2 BCS04 is the report effective date.

3 BCS06 is the program name.

$4 \mathrm{BCS07}$ is the program number identification.

$5 \mathrm{BCS10}$ is the customer share ratio number.

$6 \mathrm{BCS} 11$ is the contractor share ratio number.

7 BCS12 is the notation for the total project monetary costs.

If BCS12 is absent, the total project monetary costs are assumed to be whole dollar amounts.

Data

Ref. Element

Must Use

$$
\text { Des. }
$$

Name

Transaction Set Purpose Code

Code identifying purpose of transaction set

00

05

14

20

22

Original status data.

Replace

Advance Notification

Final Transmission reporting period.

Information Copy

\section{Data Element Summary}

Must Use BCS02

Must Use

373 Date
This code is typically used for transmitting the funds

Use this code to overwrite any previously transmitted data for a given reporting period - i.e., old data is deleted and new data is entered into the database.

Use this code in the event preliminary funds status data must be transmitted for a given reporting period. This preliminary transmission is then followed with a final transmission (code 20) to provide the final funds status data for the given reporting period.

Use this code to transmit final funds status data when preliminary data (code 14) has been sent for a given

M DT 6/6

Date (YYMMDD)

Enter the date the data report was created. This date is used for reference purposes only. 
Date (YYMMDD)

\section{Enter the report effective date, this is typically the reporting period end date.}

Must Use

BCS05

1166

Contract Type Code

O ID $2 / 2$

Code identifying a contract type

$\begin{array}{ll}\text { CW } & \text { Cost Plus Award Fee } \\ \text { CX } & \text { Cost Plus Fixed Fee } \\ \text { CY } & \text { Cost Plus Incentive Fee } \\ \text { FD } & \text { Fixed Price Redetermination } \\ \text { FE } & \text { Fixed Price with Escalation } \\ \text { FI } & \text { Fixed Price Incentive } \\ \text { FR } & \text { Firm Fixed Price } \\ \text { OC } & \text { Other Contract Type }\end{array}$

A type of contract which is neither covered by an existing code nor previously mutually defined

Use the REF (1/030) segment to provide a description of the contract type when this code is used.

TM

Time and Materials

Must Use BCS06

Not Used

Not Used

Not Used

BCS10

BCS11

BCS12

Not Used
352

Description

A free-form description to clarify the related data elements and their content
127

Reference Number

Reference number or identification number as defined for a particular Transaction Set, or as specified by the Reference Number Qualifier.

Program Type Code

Codes identifying a program type

BCS09 786

Security Level Code

O ID $2 / 2$

Code indicating the level of confidentiality assigned by the sender to the information following

Typically all data is assumed to be company proprietary information and is treated as government non-classified information (code 90). In the event codes 92,93 , or 94 are used, additional security measures such as encryption are used to protect the data.

$\begin{array}{ll}11 & \text { Competition Sensitive } \\ 90 & \text { Government Non-Classified } \\ 92 & \text { Government Confidential } \\ 93 & \text { Government Secret } \\ 94 & \text { Government Top Secret }\end{array}$

Percent

Percentage expressed as a decimal

$\begin{array}{lll}O & \text { R } & 1 / 10\end{array}$

Percent

Percentage expressed as a decimal

355 Unit or Basis for Measurement Code
O R $\quad$ 1/10

O ID $2 / 2$

Code specifying the units in which a value is being expressed, or manner in which a measurement has been taken Use this data element to indicate all total contract monetary ainounts have been factored (for example, numbers represent dollars in thousands). Use the CFT (Cost Reporting Format Type) segment to indicate the monetary anount factor used for a given funds status report at the detail level.

DO Dollars, U.S. 

factored by a hundred - i.e., hundreds of dollars. Thousands of Dollars

Millions of Dollars 
Segment: REF Reference Numbers

Position: 030

Loop:

Level:

Usage:

Max Use:

Purpose:

Syntax Notes:

Semantic Notes:

Optional

100

To specify identifying numbers.

1 At least one of REF02 or REF03 is required.

Comments:

Ref.

Data

Des.

Element Name

Data Element Summary

Must Use REF01

128

Reference Number Qualifier

$\underline{\text { Attributes }}$

Code qualifying the Reference Number.

Funds Authorization

Reference numbers to identify funds authorization (document or other reference number) in the government contracting environment

Use this code to provide a unique reference number for this Project Cost Reporting (839) transaction set and contract funds status data. Enter the unique reference number for this transaction set in REF02. Use this code only one time for each 839 transaction set.

AT

Appropriation Number

Typically, CFT08 (Appropriation Code) is used to identify the type or general category of appropriation. Use this code along with REFO3 to provide a description of the appropriation (name). This code can also be used when CFT08 is code "ZZ" (used for other appropriation types) to provide a description of the appropriation type.

C4 Change Number

Use this code to identify the latest modification number associated with the contract number. Enter the number in REF02.

CT Contract Number

Use this code when BCS05 is code "OC" for other contract types. Enter the description of the contract type in REF03.

DX Department/Agency Number

Use this code to provide a DoD Component name.

Enter the name of the DoD Component in REF03.

REF02

Reference Number

X AN 1/30

Reference number or identification number as defined for a particular Transaction Set, or as specified by the Reference Number Qualifier.

Use this data element when REF01 is code 93 or C4. 
839F Project Cost Reporting (Funds Status)

A free-form description to clarify the related data elements and their content Use this data element when REFOI is code $A T, C T$, or $D X$. 


\section{Segment: AMT Monetary Amount}

Position: 050

Loop:

Level:

Usage: Optional (Must Use)

Max Use: $\quad 30$

Purpose: To indicate the total monetary amount

Syntax Notes:

Semantic Notes:

Comments:

Notes:

Ref. Data

Des. Element Name

Must Use AMT01

\section{Data Element Summary}

This segment is required. Use this segment to provide all header (i.e., title block) monetary amount information.

\section{Amount Qualifier Code}

Code to qualify amount

$\underline{\text { Attributes }}$

M ID $1 / 2$
64

65

66

67

Initial Contract Price Target

Value of initial negotiated contract target price

Initial Contract Price Ceiling

Value of initial negotiated contract ceiling price

Adjusted Contract Price Target

Value of initial contract plus supplemental agreements

Adjusted Contract Price Ceiling

Value of adjusted ceiling price

$\begin{array}{llllll}\text { Must Use } & \text { AMT02 } & 782 & \begin{array}{l}\text { Monetary Amount } \\ \text { Monetary amount } \\ \text { For all monetary amounts, if entering factored monetary amount such as } \\ \text { thousands of dollars (notation from BCS12), use only one decimal place } \\ \text { when applicable }\end{array} \\ \text { Not Used } & \text { AMT03 } & 478 & \begin{array}{l}\text { Credit/Debit Flag Code } \\ \text { Code indicating whether amount is a credit or debit }\end{array}\end{array}$


Segment: DTM Date/Time Reference

Position: 070

Loop:

Level:

Usage: Optional (Must Use)

Max Use: $\quad 30$

Purpose: To specify pertinent dates and times

Syntax Notes: 1 At least one of DTM02 DTM03 or DTM06 is required.

2 If either DTM06 or DTM07 is present, then the other is required.

Semantic Notes:

Comments:

Notes:

This segment is required. Use this segment to provide all header (i.e., title block) date information.
Must Use DTM01

Ref.

Des.

DTM01

\section{Data Element Summary}

Data

Element Name

374 Date/Time Qualifier

Code specifying type of date or time, or both date and time

\section{Attributes}

M ID 3/3
283

284

723

724
Funds Appropriation - Start

The date that funds appropriation begins

Use this code to indicate the beginning date for the contract funding.

Funds Appropriation - End

The date that funds appropriation ends

Use this code to indicate the ending date for the contract funding.

Current Month Ending

Use this code to indicate the current report date for the funds status data.

Previous Month Ending

Use this code to indicate the previous report date for the funds status data.
Must Use DTM02
373
Date
X DT $6 / 6$
Date (YYMMDD)
Not Used DTM03
337 Time
X TM 4/8
Time expressed in 24-hour clock time as follows: HHMM, or HHMMSS, or HHMMSSD, or HHMMSSDD, where $\mathrm{H}=$ hours (00-23), $\mathrm{M}=$ minutes (00- 59), $\mathrm{S}=$ integer seconds (00-59) and $\mathrm{DD}=$ decimal seconds; decimal seconds are expressed as follows: $\mathrm{D}=$ tenths $(0-9)$ and $\mathrm{DD}=$ hundredths $(00-99)$
Not Used DTM04 Time Code O ID $2 / 2$
Code identifying the time. In accordance with International Standards Organization standard 8601 , time can be specified by a + or - and an indication in hours in relation to Universal Time Coordinate (UTC) time; since + is a restricted character, + and - are substituted by $\mathrm{P}$ and $\mathrm{M}$ in the codes that follow
$\begin{array}{lr}\text { Not Used } & \text { DTM05 } \\ \text { Not Used } & \text { DTM06 } \\ \text { Not Used } & \text { DTM07 }\end{array}$
624 Century
O NO 2/2
The first two characters in the designation of the year (CCYY)
1250 Date Time Period Format Qualifier $X \quad$ ID $2 / 3$
Code indicating the date format, time format, or date and time format
Expression of a date, a time, or range of dates, times or dates and times 
839F Project Cost Reporting (Funds Status)

Segment: CFI cost Reporting Format Type

Position: 080

Loop: CFT Mandatory

Level:

Usage:

Max Use:

Mandatory

Purpose:

Syntax Notes:

Semantic Notes:

Comments:

1

To identify the cost reporting type, type of units reported, and funds details for the

Contract Funds Status Report (CFSR)

1 If CFT01 equals CY, then CFT03, CFT04, CFT05, CFT06, CFT07 and CFT08 are required.

2 CFT02 is the notation for the report monetary costs or quantities.

If CFT02 is blank, the report monetary costs are assumed to be in whole dollar amounts.

3 CFT04 and CFT05 are used for the funds appropriation start date.

4 CFT06 and CFT07 are used for the funds appropriation end date.

Comments:

Must Use $\begin{array}{cc}\text { Ref. } & \text { Des. } \\ \text { CFT01 } & \frac{\text { Element }}{755}\end{array}$

Must Use CFT02

355

\section{Data Element Summary}
Name
Report Type Code
$\underline{\text { Attributes }}$
Code indicating the title or contents of a document, report or supporting item $\mathrm{CY}$ Contract Funds Status Report (CFSR)
Status report for funds appropriation including commitments, actual cost, forecast of billings, and estimated termination costs

Unit or Basis for Measurement Code $\quad O$ ID 2/2

Code specifying the units in which a value is being expressed, or manner in which a measurement has been taken

Use this data element to indicate the monetary amount factor for the funds status report detail data.

$\begin{array}{ll}\text { DO } & \begin{array}{l}\text { Dollars, U.S. } \\ \text { Use this code when the monetary amounts have NOT } \\ \text { been factored. }\end{array} \\ \text { HU } & \begin{array}{l}\text { Hundred } \\ \text { Use this code to indicate the monetary amounts have } \\ \text { been factored by a hundred -- i.e., hundreds of dollars. }\end{array} \\ \text { R5 } & \begin{array}{l}\text { Thousands of Dollars } \\ \text { R6 }\end{array} \\ \text { Millions of Dollars }\end{array}$

CFT03

1198

Contracting Funding Code

O ID $2 / 2$

Code identifying the funding type

01

02

03

CFT04
Multi-Year Procurement

Contract procurement that extends beyond one year

Incrementally Funded Contract (INC)

Contract funded in increments based on agreed performance criteria

Contract for a Single Year (SYC)

Funding for a contract for a single, specific year

\section{Date/Time Qualifier}

O ID $3 / 3$

Code specifying type of date or time, or both date and time
090
Report Start 
Date (YYMMDD)

For contracts which are financed with funds appropriated in more than one fiscal year, enter the fiscal year start date for this report.

CFT06

CFT07

CFT08
374

373

1199
Date/Time Qualifier

O ID $3 / 3$

Code specifying type of date or time, or both date and time

$091 \quad$ Report End

Date

Date (YYMMDD)

For contracts which are financed with funds appropriated in more than one fiscal year, enter the fiscal year ending date for this report.

$\begin{array}{lll}\text { Appropriation Code } & \text { O } & \text { ID } 2 / 2 \\ \text { Code indicating the funds appropriation } & & \end{array}$

Research, Development, Test \& Evaluation (RDT\&E)

Procurement (PROC)

02

Operations and Maintenance (O\&M)

03

Military Construction (MILCOM)

04

Mutually Defined

Use this code when other appropriation types need to be identified. Use the REF (1/030) segment to provide this information (REFOI is code AT, REFO3 contains the appropriation description). 
Segment:

Position:

Loop:

Level:

Usage:

Max Use:

Purpose:

Syntax Notes:

Semantic Notes:

Comments:

Notes:

Ref.

Des.

Must Use

CAL01

Must Use

CAL02

127

Data

Element

128

Name

Reference Number Qualifier

Code qualifying the Reference Number.

\section{Data Element Summary}

70

Calendar Number

Identifies a working calendar (for example, Monday through Friday) for a company, division, or labor group

Attributes

M ID 2/2

M AN 1/30

Reference number or identification number as defined for a particular Transaction Set, or as specified by the Reference Number Qualifier.

Enter the period number "1", "2", "3", "4", "5", "6", "7", "8", or "9" to identify the projected time frames.

$\begin{array}{ccc}\text { Not Used } & \text { CAL03 } & 344 \\ \text { Not Used } & \text { CAL04 } & 374 \\ \text { Not Used } & \text { CAL05 } & 373 \\ \text { Not Used } & \text { CAL06 } & 337\end{array}$

Not Used

CAL07

623

Unit of Time Period or Interval

O ID $2 / 2$

Code indicating the time period or interval

374 Date/Time Qualifier

O ID $3 / 3$

Code specifying type of date or time, or both date and time

Date

Date (YYMMDD)

O DT $6 / 6$

337

Time

O TM $4 / 8$

Time expressed in 24-hour clock time as follows: HHMM, or HHMMSS, or HHMMSSD, or HHMMSSDD, where $\mathrm{H}=$ hours $(00-23), \mathrm{M}=$ minutes $(00-$

$59), \mathrm{S}=$ integer seconds (00-59) and $\mathrm{DD}=$ decimal seconds; decimal seconds are expressed as follows: $\mathrm{D}=$ tenths $(0-9)$ and $\mathrm{DD}=$ hundredths $(00-99)$
Time Code
O ID $2 / 2$

Code identifying the time. In accordance with International Standards Organization standard 8601 , time can be specified by a + or - and an indication in hours in relation to Universal Time Coordinate (UTC) time; since + is a restricted character, + and - are substituted by $\mathrm{P}$ and $\mathrm{M}$ in the codes that follow

\begin{tabular}{ccc} 
Not Used & CAL08 & 678 \\
Not Used & CAL09 & 374 \\
Not Used & CAL10 & 373 \\
Not Used & CAL11 & 337 \\
\hline
\end{tabular}
Ship/Delivery or Calendar Pattern Code

O ID $1 / 2$

Code which specifies the routine shipments, deliveries, or calendar pattern
Date/Time Qualifier
O ID $3 / 3$
Code specifying type of date or time, or both date and time

Date

O DT $6 / 6$

\section{Date (YYMMDD)}

Time

O TM $4 / 8$

Time expressed in 24-hour clock time as follows: HHMM, or HHMMSS, or HHMMSSD, or HHMMSSDD, where $\mathrm{H}=$ hours (00-23), $\mathrm{M}=$ minutes $(00-$ $59), \mathrm{S}=$ integer seconds (00-59) and $\mathrm{DD}=$ decimal seconds; decimal seconds are expressed as follows: $\mathrm{D}=$ tenths $(0-9)$ and $\mathrm{DD}=$ hundredths $(00-99)$ 


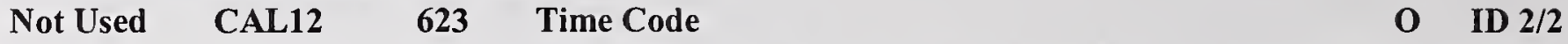

Code identifying the time. In accordance with International Standards

Organization standard 8601 , time can be specified by a + or - and an indication in hours in relation to Universal Time Coordinate (UTC) time; since + is a

restricted character, + and - are substituted by $\mathrm{P}$ and $\mathrm{M}$ in the codes that follow

$\begin{array}{llll}\text { Not Used } & \text { CAL13 } & 678 & \begin{array}{l}\text { Ship/Delivery or Calendar Pattern Code } \\ \text { Code which specifies the routine shipments, deliveries, or calendar pattern }\end{array}\end{array}$

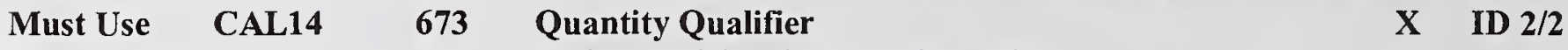

Code specifying the type of quantity

$10 \quad$ Calendar Units

The number of calendar units such as 1 per day or 1 per week

$\begin{array}{llll}\text { Must Use } & \text { CAL15 } 380 & \begin{array}{l}\text { Quantity } \\ \text { Numeric value of quantity }\end{array}\end{array}$

Enter the number of reporting months (or periods) for the projected time frame. For example, enter "3" for a quarter year, enter "12" for a fiscal or calendar year.

CAL16

Free-form Description

O AN 1/45

Free-form descriptive text

Enter a short description of the projected time frame (for example, "FY98"). A maximum of four characters is recommended. This data element is optional. 
Segment: BSD Breakdown Structure Description

Position: 090

Loop: BSD Optional (Must Use)

Level:

Usage: Optional (Must Use)

Max Use: 1

Purpose: To define discrete line items within industry or government reports

Syntax Notes: 1 At least one of BSD02 or BSD03 is required.

Semantic Notes: 1 BSD05 is the summary level structure code reference.

Comments: 1 BSD07 is the summary level reporting structure identification.

Notes: This segment is required.

Ref. Data

Des. Element Name

Must Use $\quad$ BSD01 $128 \quad$ Reference Number Qualifier

Code qualifying the Reference Number.

\section{Data Element Summary}

74

Work Breakdown Structure (WBS)

A product-oriented family tree composed of hardware, software, services, and data that completely defines the project or program

Must Use BSD02

127

Reference Number

X AN 1/30

Reference number or identification number as defined for a particular

Transaction Set, or as specified by the Reference Number Qualifier.

Enter the appropriate element code. The receiving application for the government may have certain requirements for the element codes. Confirm any element code requirements (content and number of characters) with your customer.

BSD03

352

Description

$X \quad$ AN $1 / 80$

A free-form description to clarify the related data elements and their content

This description is optional.

$\begin{array}{ll}\text { Must Use } & \text { BSD04 } \\ \text { Not Used } & \text { BSD05 } \\ & \\ & \text { BSD06 }\end{array}$

1178

Level

O AN 1/3

Reporting structure identification

127 Reference Number

O AN 1/30

Reference number or identification number as defined for a particular Transaction Set, or as specified by the Reference Number Qualifier.

1196 Breakdown Structure Detail Code

O ID $2 / 2$

Codes identifying details relating to a reporting breakdown structure tree

01

02

04

06

07

08

33

34
Labor

Direct labor costs

Material

Direct material

Subcontract

Direct subcontract

Labor Overhead

Indirect costs associated with direct labor

Material Overhead

Indirect costs associated with direct material

Other Overhead

Indirect costs associated with other direct costs

General \& Administrative

Cost of Money 
839F Project Cost Reporting (Funds Status)

$35 \quad$ Profit or Fee

Not Used BSD07 $1178 \quad$ Level

O AN 1/3

Reporting structure identification

Not Used $\quad$ BSD08 $786 \quad$ Security Level Code

O ID $2 / 2$

Code indicating the level of confidentiality assigned by the sender to the information following 
Segment: REF Reference Numbers

Position: 100

Loop: BSD Optional (Must Use)

Level:

Usage: Optional

Max Use: 100

Purpose: To specify identifying numbers.

Syntax Notes: 1 At least one of REF02 or REF03 is required.

Semantic Notes:

Comments:

Ref. Data

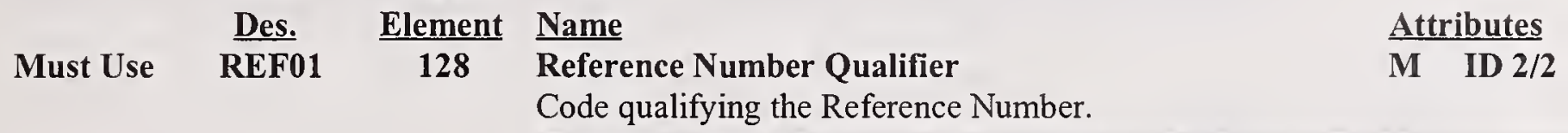

\section{Data Element Summary}

The receiving application for the government may have certain requirements for the REF qualifiers you can use and the number of characters that can be entered in REF02. Confirm these details with your customer.

\begin{tabular}{|c|c|}
\hline \multirow[t]{2}{*}{ AT } & Appropriation Number \\
\hline & $\begin{array}{l}\text { Use this code to provide an appropriation } \\
\text { identification for the element code described in } \\
\text { BSD02. Use this code only one time for each BSD } \\
\text { reference. }\end{array}$ \\
\hline \multirow[t]{2}{*}{ IX } & Item Number \\
\hline & $\begin{array}{l}\text { Use this code for other line item reference numbers } \\
\text { that relate to the element described in BSD02. Use } \\
\text { this code only one time for each BSD reference. }\end{array}$ \\
\hline
\end{tabular}

$\begin{array}{cccl}\text { Must Use } & \text { REF02 } & \mathbf{1 2 7} & \begin{array}{l}\text { Reference Number } \\ \text { Reference number or identification number as defined for a particular } \\ \text { Transaction Set, or as specified by the Reference Number Qualifier. } \\ \text { Description } \\ \text { A free-form description to clarify the related data elements and their content }\end{array} \text { Not Used } \quad \text { REF03 } \\ \text { 352 }\end{array}$


Segment: DTM Date/Time Reference

Position: 105

Loop: BSD Optional (Must Use)

Level:

Usage: Optional

Max Use: $\quad 50$

Purpose: To specify pertinent dates and times

Syntax Notes: 1 At least one of DTM02 DTM03 or DTM06 is required.

2 If either DTM06 or DTM07 is present, then the other is required.

Semantic Notes:

Comments:

Notes:

Use this segment to provide any applicable date information for the element described in BSD02. Typically, this is the fiscal year that applies to the line item or element.

Ref. Data

Des. Element Name

\section{Data Element Summary}

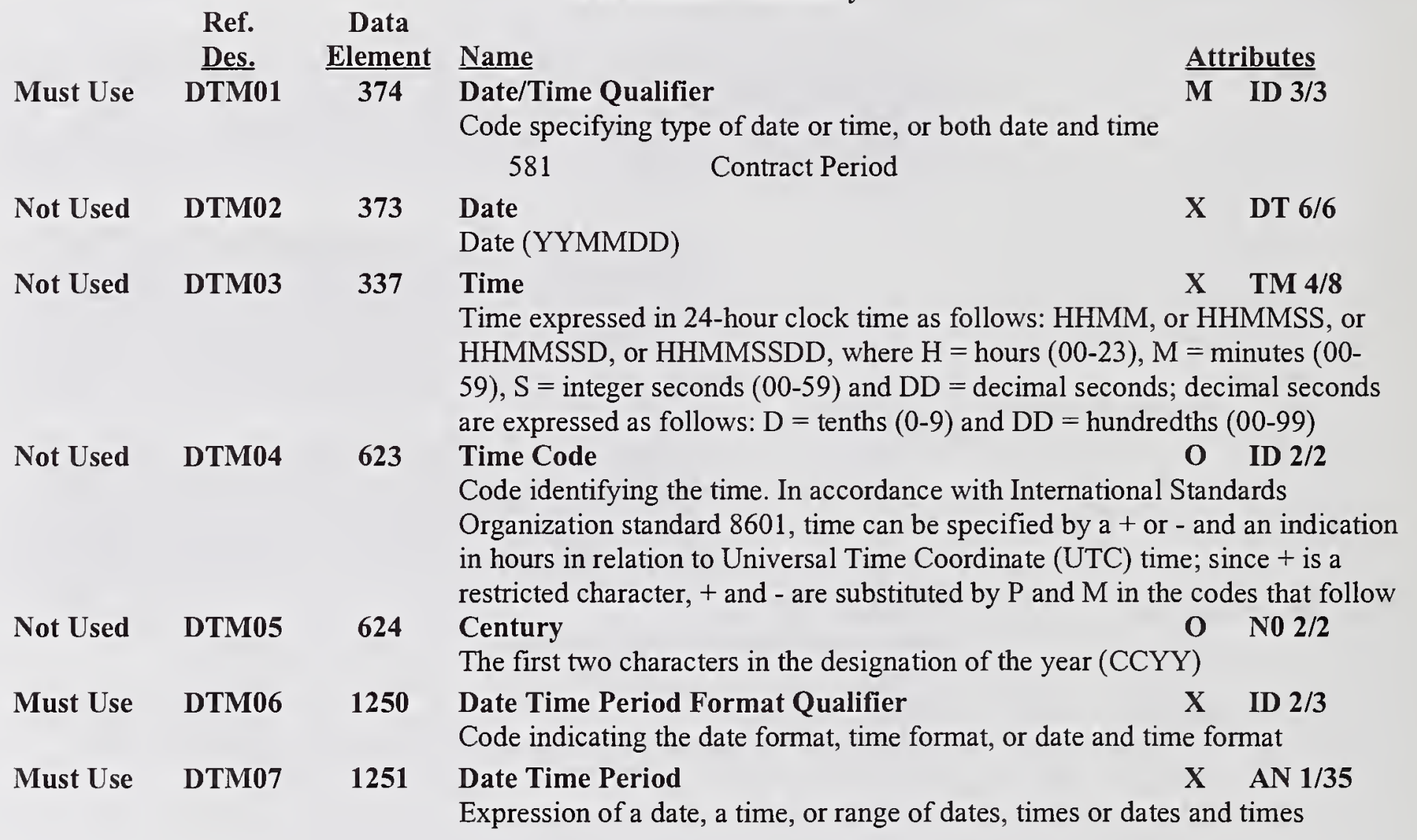




$\begin{aligned} \text { Segment: } & \text { AMI Monetary Amount } \\ \text { Position: } & 110 \\ \text { Loop: } & \text { BSD Optional (Must Use) } \\ \text { Level: } & \\ \text { Usage: } & \text { Optional (Must Use) } \\ \text { Max Use: } & 100 \\ \text { Purpose: } & \text { To indicate the total monetary amount } \\ \text { Syntax Notes: } & \\ \text { Semantic Notes: } & \\ \text { Comments: } & \text { This segment is required. }\end{aligned}$

Ref. Data

Des. Element Name

Must Use AMT01 $522 \quad$ Amount Qualifier Code

Attributes

M ID 1/2
68

69

70

71

72

Funds Authorized to Date

Value of contract fund authorized from the beginning through the current reporting period Accrued Expenditures Actual cost to date Use this code for actual to date values.

Open Commitments

Value of supplies or other items committed to for payment (such as on delivery of products)

Use this code for actual to date values.

\section{Forecast of Billings}

This is a forecast of billings to the government; includes cummulative amounts already billed (including progress or advance payments) and a forecast of amounts that will be billed to the government Use this code for actual to date values.

\section{Estimated Termination Costs}

Cost that would be necessary to liquidate all government obligations if the contract were to be ended in that reporting period Use this code for actual to date values.

Accrued Expenditures plus Open Commitments

Sum of actual costs and committed costs Contract Work Authorizied - Definitized

The estimated price for the authorized work including profit or fee, and incentive and cost sharing associated with projected over or under runs Contract Work Authorized - Not Definitized The estimate of the fund requirements for performing required work that firm contract prices have not yet been agreed to Contract Work Authorized - Total

Sum of Contract Work Authorized - Definitized and Contract Work Authorized - Not Definitized Typically this value is calculated. Confirm with your 
customer if you need to transmit this information.

Forecast of Work - Not Yet Authorized

An estimate of fund requirements including fee or profit for changes proposed, but not yet directed by the customer

Forecast of Work - All Other

An estimate of fund requirements for additional work that the contractor expects to do Forecast of Work - Total

Sum of Forecast Work - Not Yet Authorized and Forecast of Work - All Other Typically this value is calculated. Confirm with your customer if you need to transmit this information.

Funding - Total Requirements

The estimate of total fund requirements for contract work authorized and forecast Typically this value is calculated. Confirm with your customer if you need to transmit this information.

\section{Funds Carryover}

For incrementally funded contract, this is the amount that the prior Federal fiscal year funding was in excess of the prior year's requirement

Net Funds Required

An estimate of net funds required, less funds carryover Typically this value is calculated. Confirm with your customer if you need to transmit this information.

Must Use AMT02

Not Used
Monetary Amount Monetary amount For all monetary amounts, if entering factored amounts such as thousands of dollars (notation from CFT02), use only one decimal place when applicable.

478
M R $\quad$ 1/15
Credit/Debit Flag Code

Code indicating whether amount is a credit or debit 
839F Project Cost Reporting (Funds Status)

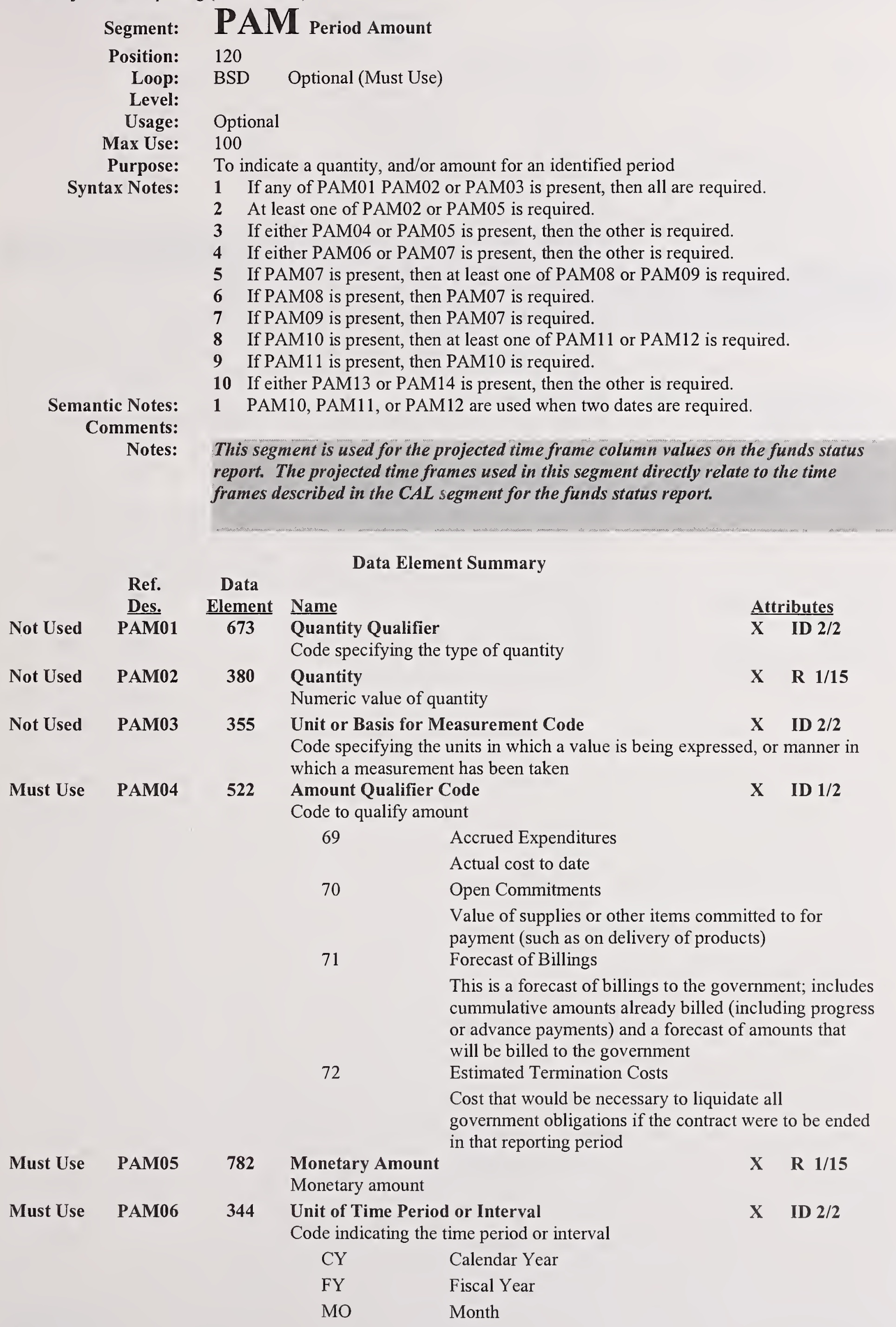




$\begin{array}{ll}\text { QY } & \text { Quarter of a Year } \\ \text { SA } & \text { Semiannual }\end{array}$

Must Use PAM07

Not Used PAM09

Not Used PAM10

Not Used PAM11

Not Used PAM12

Not Used

PAM13

1004

Not Used

PAM14

374

373
Date/Time Qualifier

Code specifying type of date or time, or both date and time

$\begin{array}{ll}174 & \text { Month Ending } \\ 194 & \text { Period End } \\ 404 & \text { Year Ending }\end{array}$

373 Date

Date (YYMMDD)

Enter the month, period, or year ending date.

\section{Time}

X TM 4/8

X DT 6/6

Time expressed in 24-hour clock time as follows: HHMM, or HHMMSS, or HHMMSSD, or HHMMSSDD, where $\mathrm{H}=$ hours (00-23), $\mathrm{M}=$ minutes (0059), $\mathrm{S}=$ integer seconds (00-59) and $\mathrm{DD}=$ decimal seconds; decimal seconds are expressed as follows: $\mathrm{D}=$ tenths $(0-9)$ and $\mathrm{DD}=$ hundredths $(00-99)$

374 Date/Time Qualifier

$\mathrm{X}$ ID $3 / 3$

Code specifying type of date or time, or both date and time

Date

Date (YYMMDD)

X DT 6/6

337 Time

X TM 4/8

Time expressed in 24-hour clock time as follows: HHMM, or HHMMSS, or HHMMSSD, or HHMMSSDD, where $\mathrm{H}=$ hours (00-23), $\mathrm{M}=$ minutes (0059), $\mathrm{S}=$ integer seconds (00-59) and $\mathrm{DD}=$ decimal seconds; decimal seconds are expressed as follows: $\mathrm{D}=$ tenths $(0-9)$ and $\mathrm{DD}=$ hundredths $(00-99)$
Percent Qualifier
$\mathrm{X}$ ID $1 / 2$
Code to qualify percent
Percent
X R $\quad \mathbf{1 / 1 0}$ 
Segment: MSG Message Text

Position: $\quad 140$

Loop: BSD Optional (Must Use)

Level:

Usage: Optional

Max Use: $\quad 1000$

Purpose: To provide a free form format that would allow the transmission of text information.

Syntax Notes:

Semantic Notes:

Comments:

1 MSG02 is not related to the specific characteristics of a printer, but identifies top of page, advance a line, etc.

Notes: Use this segment if you need to provide limited remarks or comments about the funds status data. Use is limited to 100 repetitions, any format is fine.

\section{Ref. Data}

Des. Element Name

Must Use MSG01

Free-form message text

\section{Not Used MSG02 934 Printer Carriage Control Code}

A field to be used for the control of the line feed of the receiving printer

\section{Attributes}

M AN 1/264

O ID $2 / 2$
ving printer 
Segment: N1 Name

Position: 150

Loop: N1 Mandatory

Level:

Usage:

Max Use:

Purpose:

Syntax Notes:

Semantic Notes:

Comments:

Mandatory

1

To identify a party by type of organization, name, and code

1 At least one of $\mathrm{N} 102$ or $\mathrm{N} 103$ is required.

2 If either N103 or N104 is present, then the other is required.

1 This segment, used alone, provides the most efficient method of providing organizational identification. To obtain this efficiency the "ID Code" (N104) must provide a key to the table maintained by the transaction processing party.

2 N105 and N106 further define the type of entity in N101.

Notes: Whenever possible, identification and address information should be provided using N101, N103, and N104. Use N102 and segments N2, N3, and N4 as applicable when this information cannot be provided by using one of the codes listed in N103.

Ref. Data

$\begin{array}{llcll}\text { Must Use } & \text { Des. } & \text { Element } & & \text { Name } \\ \text { N101 } & 98 & & \text { Attributes } \\ \text { Entity Identifier Code } & \text { ID 2/2 }\end{array}$

\section{Data Element Summary}

entity, a physical location, or an individual

FR

Message From

Use this code to identify the organization sending the funds status data.

TO

Message To

Use this code to identify the organization receiving the funds status data.

ZD

Party to Receive Reports

The organization designated to receive reports

Use this code to identify the organization that receives an information copy of the funds status data.

N102

N103

Not Used

Not Used
N105

N106
93 Name

Free-form name

66

Identification Code Qualifier

Code designating the system/method of code structure used for Identification Code (67)

1

9

33
$\mathrm{X}$ AN $1 / 35$

X ID $1 / 2$
10
D-U-N-S Number, Dun \& Bradstreet

D-U-N-S+4, D-U-N-S Number with Four Character Suffix

Department of Defense Activity Address Code (DODAAC)

Commercial and Government Entity (CAGE)

67 Identification Code

$\mathrm{X}$ AN 2/20

Code identifying a party or other code

706

Entity Relationship Code

O ID $2 / 2$

Code describing entity relationship

98 Entity Identifier Code

O ID $2 / 2$

Code identifying an organizational entity, a physical location, or an individual 
839F Project Cost Reporting (Funds Status)

Segment: $\quad$ 2 Additional Name Information

Position: 160

Loop: N1 Mandatory

Level:

Usage: Optional

Max Use: 1

Purpose: To specify additional names or those longer than 35 characters in length

Syntax Notes:

Semantic Notes:

Comments:

Notes: This segment should only be used when N102 is used and it is necessary to provide additional name information.

Ref. Data

Data Element Summary

Des. Element Name

Must Use N201 $93 \quad$ Name

Free-form name

N202

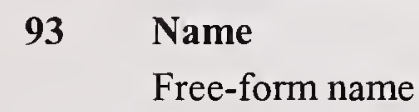

Attributes

M AN 1/35

O AN 1/35 
839F Project Cost Reporting (Funds Status)

Segment: N3 Address Information

Position: 170

Loop: N1 Mandatory

Level:

Usage: Optional

Max Use: 1

Purpose: To specify the location of the named party

Syntax Notes:

Semantic Notes:

Comments:

Notes:

This segment should only be used when N102 is used.

Ref. Data

Des. Element Name

Must Use

166

Address Information

Address information

N302

Address Information

\section{Data Element Summary}

Address information
Attributes

M AN 1/35

O AN 1/35 
839F Project Cost Reporting (Funds Status)

Segment: N4 Geographic Location

Position: 180

Loop: N1 Mandatory

Level:

Usage: Optional

Max Use: 1

Purpose: To specify the geographic place of the named party

Syntax Notes: 1 If N406 is present, then N405 is required.

Semantic Notes:

Comments: 1 A combination of either N401 through N404, or N405 and N406 may be adequate to specify a location.

$2 \mathrm{~N} 402$ is required only if city name (N401) is in the USA or Canada.

Notes: This segment should only be used when N102 is used.

\begin{tabular}{|c|c|c|c|c|c|}
\hline \multicolumn{6}{|c|}{ Data Element Summary } \\
\hline & $\begin{array}{l}\text { Ref. } \\
\text { Des. }\end{array}$ & $\begin{array}{c}\text { Data } \\
\text { Element }\end{array}$ & Name & \multicolumn{2}{|c|}{ Attributes } \\
\hline Must Use & $\mathrm{N} 401$ & 19 & $\begin{array}{l}\text { City Name } \\
\text { Free-form text for city name }\end{array}$ & & AN 2/30 \\
\hline Must Use & N402 & 156 & $\begin{array}{l}\text { State or Province Code } \\
\text { Code (Standard State/Province) as defined by appropriate go }\end{array}$ & & $\begin{array}{l}\text { ID } 2 / 2 \\
\text { ment agency }\end{array}$ \\
\hline Must Use & N403 & 116 & $\begin{array}{l}\text { Postal Code } \\
\text { Code defining international postal zone code excluding punc } \\
\text { (zip code for United States) }\end{array}$ & & $\begin{array}{l}\text { ID } 3 / 11 \\
\text { on and blanks }\end{array}$ \\
\hline & N404 & 26 & Country Code & $\mathbf{O}$ & ID $2 / 3$ \\
\hline & & & Code identifying the country & & \\
\hline Not Used & N405 & 309 & $\begin{array}{l}\text { Location Qualifier } \\
\text { Code identifying type of location }\end{array}$ & $\mathbf{X}$ & ID $1 / 2$ \\
\hline Not Used & N406 & 310 & $\begin{array}{l}\text { Location Identifier } \\
\text { Code which identifies a specific location }\end{array}$ & $\mathbf{O}$ & AN $1 / 30$ \\
\hline
\end{tabular}


Segment: PER Administrative Communications Contact

Position: 190

Loop: N1 Mandatory

Level:

Usage: Optional (Must Use)

Max Use: $\quad 10$

Purpose: To identify a person or office to whom administrative communications should be directed

Syntax Notes: 1 If either PER03 or PER04 is present, then the other is required.

2 If either PER05 or PER06 is present, then the other is required.

3 If either PER07 or PER08 is present, then the other is required.

Semantic Notes:

Comments:

Notes:

At least one repetition of the PER segment is required per transaction set to identify a contact person for the report. This should be a specific individual's name.

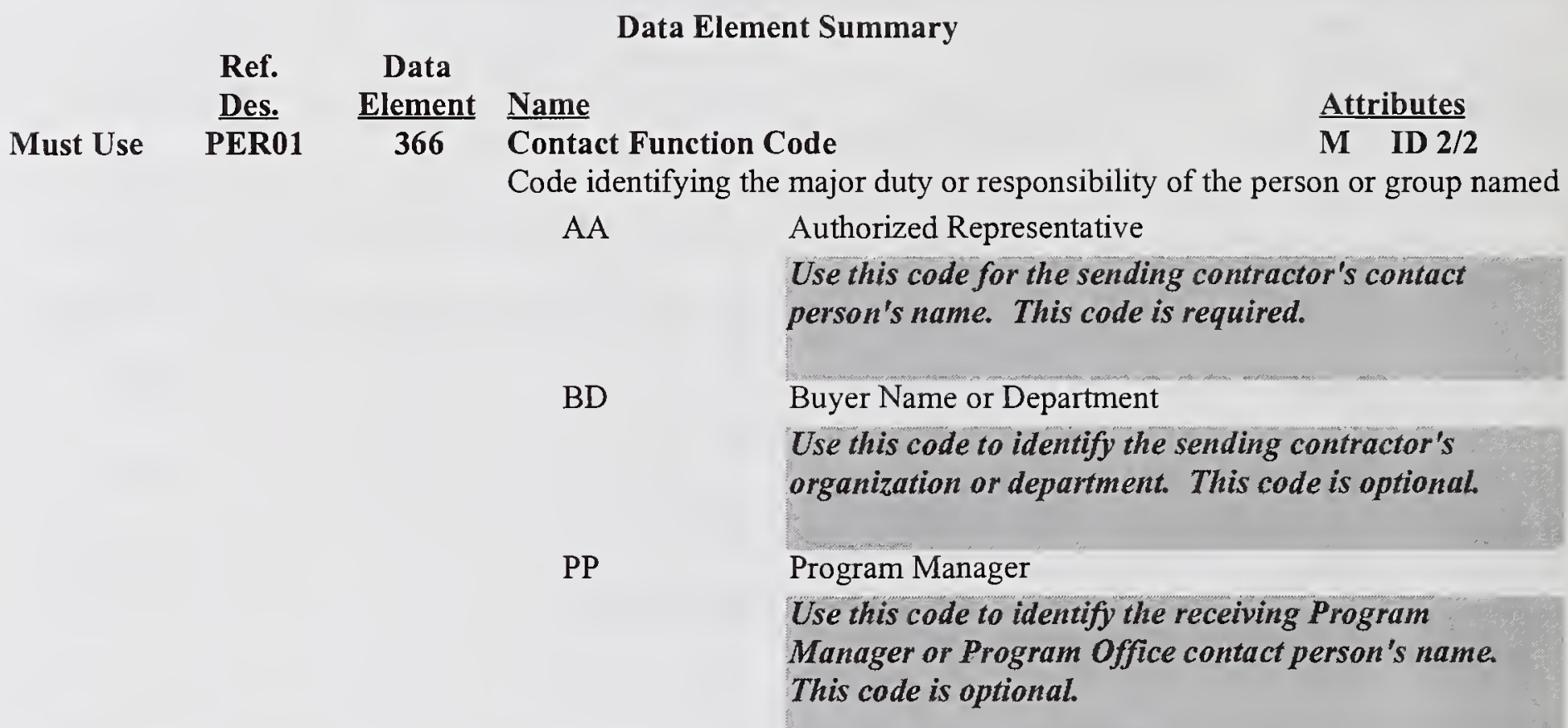

Must Use PER02 $93 \quad$ Name

O AN 1/35

Free-form name

1. When PERO1 is code AA or PP, enter the person's name. Provide the last name, first name, and middle initial if available. Include blank spaces between name components and periods after initials. Omit the comma between the last name and first name.

2. When PERO1 is code BD, enter the sending contractor's organization code or department reference.

PER03

Communication Number Qualifier

$\mathrm{X} \quad$ ID $2 / 2$

Code identifying the type of communication number

$\begin{array}{ll}\text { EM } & \text { Electronic Mail } \\ \text { FX } & \text { Facsimile } \\ \text { TE } & \text { Telephone }\end{array}$

$\begin{array}{llll}\text { PER04 } 364 & \text { Communication Number } & X & \text { AN 1/80 }\end{array}$

Complete communications number including country or area code when applicable

$\begin{array}{llll}\text { PER05 } & 365 & \text { Communication Number Qualifier } & X\end{array}$

Code identifying the type of communication number

EM Electronic Mail 


$\begin{array}{ll}\text { EX } & \text { Telephone Extension } \\ \text { FX } & \text { Facsimile } \\ \text { TE } & \text { Telephone }\end{array}$

$\begin{array}{lllll}\text { PER06 } & 364 & \text { Communication Number } & X & \text { AN 1/80 }\end{array}$

Complete communications number including country or area code when applicable

$\begin{array}{llll}\text { PER07 } & 365 & \text { Communication Number Qualifier } & X \quad \text { ID 2/2 }\end{array}$

Code identifying the type of communication number

$\begin{array}{ll}\text { EM } & \text { Electronic Mail } \\ \text { EX } & \text { Telephone Extension } \\ \text { FX } & \text { Facsimile } \\ \text { TE } & \text { Telephone }\end{array}$

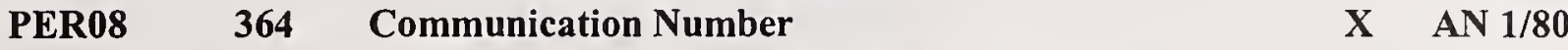

Complete communications number including country or area code when applicable

PER09 443 Contact Inquiry Reference O AN 1/20

Use this data element when PERO1 is code AA or PP to enter the title of the person named in PER02. 
Segment: DTM Date/Time Reference

Position: 200

Loop: N1 Mandatory

Level:

Usage: Optional (Must Use)

Max Use: 10

Purpose: To specify pertinent dates and times

Syntax Notes: 1 At least one of DTM02 DTM03 or DTM06 is required.

2 If either DTM06 or DTM07 is present, then the other is required.

\section{Semantic Notes:}

Comments:

Notes:

\section{This segment is required.}

\begin{tabular}{|c|c|c|c|c|c|}
\hline \multirow{8}{*}{ Must Use } & \multirow{2}{*}{\multicolumn{4}{|c|}{ Data ciement summary }} & \multirow[b]{3}{*}{ Attributes } \\
\hline & Ref. & Data & & & \\
\hline & Des. & Element & \multirow{3}{*}{\multicolumn{2}{|c|}{$\begin{array}{l}\text { Name } \\
\text { Date/Time Qualifier } \\
\text { Code specifying type of date or time, or both date and time }\end{array}$}} & \\
\hline & DTM01 & 374 & & & M ID 3/3 \\
\hline & & & & & \\
\hline & & & \multirow[t]{3}{*}{275} & \multicolumn{2}{|l|}{ Approved } \\
\hline & & & & \multicolumn{2}{|c|}{ Date report was approved by contractor representative } \\
\hline & & & & \multicolumn{2}{|c|}{$\begin{array}{l}\text { Use this code to indicate the date the data was } \\
\text { approved for submission. }\end{array}$} \\
\hline Must Use & DTM02 & 373 & \multirow{2}{*}{\multicolumn{2}{|c|}{$\begin{array}{l}\text { Date } \\
\text { Date (YYMMDD) }\end{array}$}} & DT $6 / 6$ \\
\hline & & & & & \\
\hline Not Used & DTM03 & 337 & \multicolumn{2}{|c|}{ Time } & $\mathrm{X} \quad \mathrm{TM} 4 / 8$ \\
\hline & & & \multicolumn{3}{|c|}{$\begin{array}{l}\text { Time expressed in } 24 \text {-hour clock time as follows: HHMM, or HHMMSS, or } \\
\text { HHMMSSD, or HHMMSSDD, where } \mathrm{H}=\text { hours }(00-23), \mathrm{M}=\text { minutes }(00- \\
59), \mathrm{S}=\text { integer seconds }(00-59) \text { and } \mathrm{DD}=\text { decimal seconds; decimal seconds } \\
\text { are expressed as follows: } \mathrm{D}=\text { tenths }(0-9) \text { and } \mathrm{DD}=\text { hundredths }(00-99)\end{array}$} \\
\hline Not Used & DTM04 & 623 & \multirow{3}{*}{\multicolumn{3}{|c|}{$\begin{array}{l}\text { Time Code } \\
\text { Code identifying the time. In accordance with International Standards } \\
\text { Organization standard } 8601 \text {, time can be specified by a }+ \text { or }- \text { and an indication } \\
\text { in hours in relation to Universal Time Coordinate (UTC) time; since }+ \text { is a } \\
\text { restricted character, + and - are substituted by } P \text { and } M \text { in the codes that follow }\end{array}$}} \\
\hline & & & & & \\
\hline & & & & & \\
\hline Not Used & DTM05 & 624 & \multicolumn{2}{|c|}{ Century } & $\mathrm{O} \quad$ No $2 / 2$ \\
\hline & & & \multicolumn{3}{|c|}{ The first two characters in the designation of the year (CCYY) } \\
\hline Not Used & DTM06 & 1250 & \multirow{2}{*}{\multicolumn{3}{|c|}{$\begin{array}{l}\text { Date Time Period Format Qualifier } \\
\text { Code indicating the date format, time format, or date and time format }\end{array}$}} \\
\hline & & & & & \\
\hline Not Used & DTM07 & 1251 & \multirow{2}{*}{\multicolumn{3}{|c|}{$\begin{array}{l}\text { Date Time Period } \\
\text { Expression of a date, a time, or range of dates, times or dates and times }\end{array}$}} \\
\hline & & & & & \\
\hline
\end{tabular}


Segment: $\quad$ SE Transaction Set Trailer

Position: 210

Loop:

Level:

Usage: Mandatory

Max Use: 1

Purpose: To indicate the end of the transaction set and provide the count of the transmitted

Syntax Notes: segments (including the beginning (ST) and ending (SE) segments).

Semantic Notes:

Comments: 1 SE is the last segment of each transaction set.

Ref. Data

Data Element Summary

Des. Element Name

Attributes

M NO 1/10

Number of Included Segments

Total number of segments included in a transaction set including ST and SE segments

Must Use SE02
Transaction Set Control Number

M AN 4/9

Identifying control number that must be unique within the transaction set functional group assigned by the originator for a transaction set SE02 is the same number as the number in STO2. 





\section{Periodical}

Journal of Research of the National Institute of Standards and Technology-Reports NIST research and development in those disciplines of the physical and engineering sciences in which the Institute is active. These include physics, chemistry, engineering, mathematics, and computer sciences. Papers cover a broad range of subjects, with major emphasis on measurement methodology and the bãsic technology underlying standardization. Also included from time to time are survey articles on topics closely related to the Institute's technical and scientific programs. Issued six times a year.

\section{Nonperiodicals}

Monographs-Major contributions to the technical literature on various subjects related to the Institute's scientific and technical activities.

Handbooks - Recommended codes of engineering and industrial practice (including safety codes) developed in cooperation with interested industries, professional organizations, and regulatory bodies.

Special Publications-Include proceedings of conferences sponsored by NIST, NIST annual reports, and other special publications appropriate to this grouping such as wall charts, pocket cards, and bibliographies.

National Standard Reference Data Series_-Provides quantitative data on the physical and chemical properties of materials, compiled from the world's literature and critically evaluated. Developed under a worldwide program coordinated by NIST under the authority of the National Standard Data Act (Public Law 90-396). NOTE: The Journal of Physical and Chemical Reference Data (JPCRD) is published bimonthly for NIST by the American Chemical Society (ACS) and the American Institute of Physics (AIP). Subscriptions, reprints, and supplements are available from ACS, 1155 Sixteenth St., NW, Washington, DC 20056.

Building Science Series-Disseminates technical information developed at the Institute on building materials, components, systems, and whole structures. The series presents research results, test methods, and performance criteria related to the structural and environmental functions and the durability and safety characteristics of building elements and systems.

Technical Notes-Studies or reports which are complete in themselves but restrictive in their treatment of a subject. Analogous to monographs but not so comprehensive in scope or definitive in treatment of the subject area. Often serve as a vehicle for final reports of work performed at NIST under the sponsorship of other government agencies.

Voluntary Product Standards-Developed under procedures published by the Department of Commerce in Part 10, Title 15, of the Code of Federal Regulations. The standards establish nationally recognized requirements for products, and provide all concerned interests with a basis for common understanding of the characteristics of the products. NIST administers this program in support of the efforts of private-sector standardizing organizations.

Order the following NIST publications-FIPS and NISTIRs-from the National Technical Information Service, Springfield, VA 22161.

Federal Information Processing Standards Publications (FIPS PUB)-Publications in this series collectively constitute the Federal Information Processing Standards Register. The Register serves as the official source of information in the Federal Government regarding standards issued by NIST pursuant to the Federal Property and Administrative Services Act of 1949 as amended, Public Law 89-306 (79 Stat. 1127), and as implemented by Executive Order 11717 (38 FR 12315, dated May 11, 1973) and Part 6 of Title 15 CFR (Code of Federal Regulations).

NIST Interagency Reports (NISTIR)-A special series of interim or final reports on work performed by NIST for outside sponsors (both government and nongovernment). In general, initial distribution is handicd by the sponsor; public distribution is by the National Technical Information Scrvicc, Springfield, VA 22161, in paper copy or microfiche form. 


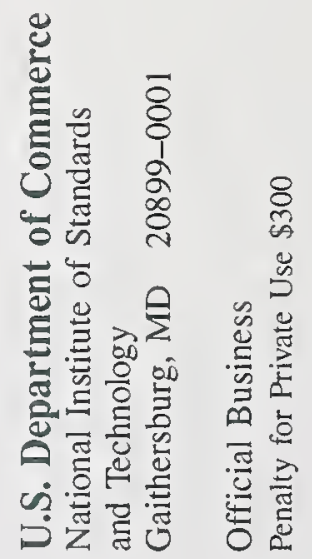

